\title{
KNOWLEDGE, ATTITUDE AND PRACTICE ON FOOD HYGIENE AND SANITATION, OPTIMISTIC BIAS OF FOOD HANDLERS, AND THEIR ASSOCIATION WITH PARTICIPATION IN FOOD SAFETY TRAINING AT A HOSPITAL IN YOGYAKARTA
}

\author{
R. Dwi Budiningsari, Ika Ratna Palupi \\ Department of Health Nutrition, Faculty of Medicine, Public Health, \\ and Nursing, Universitas Gadjah Mada
}

\begin{abstract}
Background: Incompatible sanitation hygiene practice during food processing in hospitals is possible due to optimism bias. This bias occurs when food handlers perceive that they are unlikely to cause foodborne illness. There is a lack of studies into this phenomenon. This study aimed to analyze knowledge, attitude, and practice of sanitation hygiene and the optimistic bias of food handlers and their relationship with participation in food safety training.
\end{abstract}

Subjects and Method: This was a cross-sectional study conducted in April to May, 2019. A sample consisting of all food handlers during the preparation, processing, and serving of food was taken at a hospital in Yogyakarta. Sample data on participation in food safety training, knowledge and attitude toward hygiene and sanitation, and optimistic bias, were collected by face-to-face interview using questionnaire and observation. Knowledge, attitude and practice with a score of more than $70 \%$ was categorized as good. The dependent variable was optimistic bias. The independent variable was attending food safety training. The data were tested by Student t.

Result: Study subjects had good food safety knowledge, attitude and practices with mean scores of 72.4\%, 71.2\%, and 97.6\%, respectively. Knowledge on sources of contamination was low (25\%). More than $50 \%$ of food handlers were talking while their worked. The food handlers perceived themselves as less likely to cause a foodborne disease, demonstrating the tendency of an optimistic bias. Food handlers who participated in training (Mean=6.40; $\mathrm{SD}=2.56)$ perceived themselves at higher risk than the untrained counterparts (Mean $=5.25 ; \mathrm{SD}=4.42)$, but this difference was statistically non-significant $(\mathrm{p}=0.454)$.

Conclusion: Food handlers have good knowledge, attitude, and practice, but they tend to demonstrate optimistic bias with may cause ignorant of food safety procedure. The optimistic bias must be redressed to improve awareness toward food safety procedure.

Keyword: sanitation hygiene, optimism bias, food handlers, food safety training participation

\section{Correspondence:}

Dwi Budiningsari. Department of Health Nutrition, Faculty of Medicine, Public Health, and Nursing. Universitas Gadjah Mada. Email: budiningsari@ugm.ac.id. Mobile: 08211969393 